\title{
Article
}

\section{Who am 'I': Reauthoring self, stories and subjectivity in research with children}

\author{
Thomas, Donna
}

Available at http://clok.uclan.ac.uk/31516/

Thomas, Donna ORCID: 0000-0002-8232-5778 (2021) Who am 'I':

Reauthoring self, stories and subjectivity in research with children. Global Studies of Childhood, 11 (3). pp. 230-241.

It is advisable to refer to the publisher's version if you intend to cite from the work. http://dx.doi.org/10.1177/2043610619900518

For more information about UCLan's research in this area go to

http://www.uclan.ac.uk/researchgroups/ and search for <name of research Group>.

For information about Research generally at UCLan please go to http://www.uclan.ac.uk/research/

All outputs in CLoK are protected by Intellectual Property Rights law, including Copyright law. Copyright, IPR and Moral Rights for the works on this site are retained by the individual authors and/or other copyright owners. Terms and conditions for use of this material are defined in the policies page. 


\section{Who am 'I': Reauthoring self, stories and subjectivity in research with children}

The 'new' sociology of childhood sees an emergence of interdisciplinary approaches to understanding self, experience and subjectivity of children. As debates frame research with children, concerned with 'ethics' (Daley, 2015; Gorin et al, 2008) and 'agency' (Larkins, 2019; Oswell, 2016), what is meant by the 'subject' of experience is given little attention. In this paper, I ask whether narratives are a true representation of 'self'; who is the 'experiencer' that stories refer to and what are the implications for claiming subjectivity through narrative structures? I suggest that 'experience' is an irreducible quality of reality that transcends personal self, and that a core subjectivity serves as the dative of experience (Kastrup, 2018), 'as natures sole ontological primitive (2018, p137). Understanding self, experience and subjectivity in line with an 'Analytical Idealism' (Kastrup, 2016, 2017a, 2017b, 2018, 2019), offers fresh insight into current sociological debates in Childhood Studies.

\section{Keywords}

'Analytical Idealism'; Children; Consciousness; Narrative; Self; Self-enquiry; 'Second attention epistemology'; Subjectivity

The 'new' sociology of childhood sees interdisciplinary approaches to the study of and research with, children (see -Holloway \& Valentine 2000; Larkin, 2016; Mayall, 2002; Mereweather, 2013; Morrow, 2008). Recent compelling theoretical and ontological contributions to the study of childhood can be seen in both critical realist interpretations (see-Larkins, 2016, 2019; Kizel, 2019), adding 'theoretical reinforcement...on relatively enduring patterns of disadvantage and potential powers' (Larkins, 2019, p1); and new materialist explanations (see Barad, 2007; Delueze \& Guittari, 1987: Connolly, 2013) that seek to explain relations between individuals, objects and non-human forces. Historically, 'children in Western societies have been seen as objects of concern rather than as persons with voice' (Lewis, 2010, p 14). Now, children are increasingly viewed as 'competent social actors' (Dixon et al, 2019, p10) with an authority grounded in lived experience. Across the minority world, children's selves are largely explored through narrative representations. For children in majority world contexts, agency is largely unexplored (see Punch, 2016), requiring 'cross-cultural dialogue' (Punch, 2016) to understand children's 'selves' in more meaningful ways. As debates frame current practice around researching with children, concerned with 'ethics' (Daley, 2015; Gorin et al, 2008) and 'agency' (Larkins, 2019), what is meant by the 'subject' of experience is given little attention. How we understand the nature of the 'l' of children is limited. In this paper, I will argue that most research processes with children in the Western world are rooted in postmodern ideas of selfhood and individualism (see Giddens, 1991), with sparse exploration of what self, experience and reality constitute and are constituted by. I explore self, experience and reality in the context of Childhood Studies, suggesting that narrative is not synonymous with 'self', nor does it represent the experiencer. I argue that a core subjectivity is the primary 'dative' of all experience (Kastrup, 2018), located 'within' and 'without' human and non-human beings. Exploring children's subjectivity within a consciousness-only ontology has global relevance in understanding a shared, primordial 'l' of experience; that transcends personhood, context and culture. I consider tensions between ideas of personal selves and assemblages as self, that are found in current postmodernism and posthuman 
approaches, in Childhood Studies. Seen as an under problemitisation 'of the politics of voice, authenticity and experience' (Oswell, 2016, p23). I propose how Kastrup's (2017a, 2017b, 2018, 2019) 'Analytical Idealism' can reconcile current tensions in social sciences between self as story, reflexive agency and posthuman ideas; in turn making significant contributions to the field of childhood studies. The paper does not seek to deny the value of children's stories in research work which informs the study of children. Instead, it offers further emancipatory ideas aimed at disentangling children from inner narrative constructs in which a limited sense of self emerges. Where stories can become tools for self-enquiry. A further aim of the paper is to offer a broader interdisciplinary approach towards the study of children, in research and more broadly, within the 'new' sociology of childhood.

\section{Childhood, Research and the Story 'I'}

Childhood studies are traditionally situated within an ontology of social constructionism. For childhood studies, social constructionism has historically positioned children as 'a variable of social analysis always positioned against other variables' (Oswell, 2016, p16). Postmodern views of children assume a reflexive agency in the form of storytelling (see Prout \& James, 1990). Stories demonstrate a weaving of personal, social, cultural and political forces, appealing to social research 'because of its unmasking of the seemingly natural as contingently constructed [opening up] possibilities for intentional personal and social change' (Alanen, 2015, p160). Despite its potential to 'unmask' forces which condition the personal, social constructionism 'reduces experience to a single dimension' (Heinich, 2010). Prioritising minds and language through 'a move [were] textuality has all but replaced the more traditional concept of reality' (Hein, 2016, p126). This has led to storytelling as a more significant source of knowledge production (see -Wexlar et al, 2012; McNamara, 2011). Traditional and now digital ethnographies (see Dennehey \& Arensman, 2019) see stories gathered 'as [youth-produced] representations of their everyday lives, values and identities' (Wexlar et al, 2012, p478). This is a worthy focus, particularly in environments were children are disempowered and silenced. The perceived value of collecting stories as authoritative knowledge about self and experience is rooted in long-standing ideas about 'self' and 'identity' (see Frank, 1995; Giddens, 1991; Labov \& Waletsky, 1969; Raccour, 1991). Frank (1995) claims how stories equate to self, as it is by 'listening to others and telling our own stories that we become who we are' (p77). Frank (1995) constitutes stories as more than a descriptive tool 'they are themselves the medium of being' (p53). Assuming that there is 'no self to be discovered outside of narrative' (Aatola, 2019, p3). Narrative identity (see Raccour, 1991) is treated as 'self' and has in Childhood Studies and in researching with children, 'paved the way for underlining the significance of hermeneutically interpreting and recounting the self (Aatola, 2019, p3).

Self or 'identity' in postmodern ontologies is a fluid and fragmented process, continually shaped and reshaped in interaction with the social world (see Giddens, 1991). Stories 'have always been important, but now, life is fitted in a reflexive modernity fostering a particular culture of storytelling' (Sandberg, 2016). Contemporary storytelling in the form of personal narratives, depart from ancient and traditional narrative functions. Now, narratives 'act as a way of reaffirming oneself in an era that interrogates identities and selves' (Charon, 2006 - cited in Aaltola, 2019, p2). In this way, narrative (re)constructs identity and offers epistemological expertise in a process of meaning-making. Narrative becomes the anchor when self is elusive 
and fragmented, while challenging systems which position society as a 'passive, faceless group' (Aatola, 2019, p2). Those concerned with narrative enquiry (see Bamberg, 2011; Georgiokoupoli, 2007) are starting to question the relationship between narrative and self, asking 'why at all do we rely on stories as seriated events of what actually happened when attempting to draw up a sense of who we are?' (Bamberg, 2011, p18). Postmodern ontologies posit discursive realities (see Foucault 1982, Fairclough \& Chouliaraki, 1999), where narrative plays a significant role in locating a sense of self in dialectical relations (see Fairclough \& Chouliaraki, 1999; Harvey, 1998), with institutional, social, cultural and behavioral elements of social life. Personal narratives are deeply intertwined with the grand institutional narratives that shape Childhood Studies and current research with children. New approaches to critical and philosophical reflexivity in practice (see - Larkins, 2016, 2019; Kizel, 2019, Warin, 2012) are starting to address this. Yet, this is not just about becoming more reflexive and critical about social roles, identities and practice. It calls for a deeper understanding of what self, experience and reality is within the study of childhood; and the roles that subjectivity, narrative and agency assume within it. What may be required is a truer enquiry into what we mean by ' $\mathrm{l}$ '.

Approaches that start from the authority of children, place narratives as a core source of knowledge production, of a body-rooted subjective 'l'. Ontological concerns with the nature-of-child are concerned with the nature of child in relation to the social, and not in and of itself. As Oswell (2016) notes:

'a statement about what children are is also a statement about their capacity to change the organisation of the social world in which they live. This strong ontological claim is articulated with a strong methodological claim regarding, not only how we might, but how we should investigate the beingness of children. Namely, the agentic presentness of children is understood in terms of children's lived experiences'

(Oswell, 2016, p16)

The ontological nature of children is sought through the story ' $I$ ' as the authority of experience; without problematising the nature of the story 'I'. As Nietzsche notes (see Spivak,1974), the story ' $I$ ' may be a "specifically linguistic figurative habit of immemorial standing" (p26). It is true that stories have a significant value for making sense of the world. Stories validate points of view (Thornborrow, 2000), maintain family bonds (Blum-Kulka, 1997), co-create peer relationships (Bamberg \& Georgikopouli, 2008) and negotiate and renegotiate a sense of self. Storytelling is a consistent feature of everyday talk (see Norrick, 2000) and the 'tellability' (Labov \& Waletsky, 1967) of personal stories are important for self-worth and a sense of belonging within community settings. Stories function as valuable tools for socialization and can promote a sense of belonging for children. Yet the value placed on assigning self to the 'I' of the narrative can disempower children. As MacSweeney et al (2018) recognise, 'a change in the nature of this focus is required-from one in which young people are the subjects or characters of research efforts to one which they are active agents or authors' (MacSweeney Et al, 2019). Children can only start to author and reauthor their stories when they can see that they are not their stories. The synonymizing of self, experience and reality in research with children means that 
the 'subject' of experience is taken for granted. Sustaining an idea that children are their stories, whether painful or soothing. If narratives are synonymous with self, then experience and reality are irreducible to story, in a postmodern understanding. On this premise, painful stories, so often (but not always) conveyed by children in research, assume a sense of self. When professionals proclaim how important story is, internal reification of 'I am my story' takes place; where 'focus is on personal becoming and the commitment to shaping oneself as a human being' (Aalotola, 2019). Stories assume and are assumed to carry an enacted agency. 'Agency' is debated and contested in current childhood studies (see Larkins, 2019; Esser, 2016; Oswell, 2016) and as Larkins (2019) suggests is a term 'used without clear definitions' (p2). What needs to be added into discussions around agency is the process of children assessing and discerning personal inner narratives about self, others and the world.

\section{The Ontologies of Children and the 'I' of experience}

The suggestion that children are not their stories does not intend to discount an inherent subjectivity, as is the case in posthuman approaches, such as new materialisms (Haraway, 1998; Bennet, 2001; Barad, 2007; Delueze \& Guitarri 1987). Delueze \& Guittari (1987) and Barad (2007) inform a new wave of childhood sociology 'where children's agency might be assembled and infra-structured within and across a range of devices, materialities, technologies and other sentient bodies' (Oswell, 2016, p26). Posthuman theories displace a human subject, and in many respects, the nature of direct experience, rejecting personal narratives in favour of a flat, non-subject ontology. A tension between the value of agent reflexivity and posthuman theories (see Simonsen, 2012) frames current approaches across social sciences, impacting upon childhood studies and in understanding children in research processes. New materialisms 'have also emerged as an important movement in qualitative inquiry' (Hein, 2016); influencing research with children. New materialism approaches have been especially useful in the study of very young children and how they experience the world (see - Mereweather, 2019). Children's embodied and sensory experiences are seen as a primary enactment of lived experience, replacing conceptual narrative structures. This embodied and non-local subjectivity emphasizes a natural 'worlding of children that does not divide children and nature or nature and culture but instead proposes mixed up worlds in which all manner of things co-exist' (Mereweather, 2019, p). Human beings are therefore seen 'as collective assemblages that zigzag across time' (Hickey et al, 2013,p183). Delueze \& Guattari (1987) suggest that 'there is no individual enunciation' shifting focus away from an individual subject towards 'the necessarily social character of enunciation' (p79). For Delueze \& Guitarri, there are no structures nor genesis of subjectivity and therefore, no agency. Differences are an accidental result of 'complex networks of forces, relations, connections and becomings' (Hein, 2016). Barad (2007) does claim an agential agency dispersed across things, rather than being an attribute of subjects and objects; an agency 'that is doing or being in its intra-activity' (Barad, 2007, p178). Subjectivity and agency is an entangled affair. Delueze \& Guitarri (1987) and Barad (2007) make significant contributions in destabilising a core, subjective and separate self. For research with children, understanding subjectivity and agency as intra-connected has real benefits for collective action, but extraordinary benefits for self-empowerment, if the idea of an individual agency can be reconciled within it. The dualistic nature of mind and matter sits in tension with the monastic underpinnings of posthumanism, where 'new materialist theories...do not interrogate the material conditions of the separation of the mental and material (Rekret, 2016, p180). Nor do they enquire into the ' $I$ ' of 
experience. The nature of self, whether viewed from the perspective of mind or matter, remains a mystery. If postmodernism pulls apart knower from known and posthumanism collapses knower and known, we are still left with questions around the knowing element of all experience. The knowing 'l' in which all phenomena (including mind, matter and the world), is known. As Oswell (2016) notes, 'it is an understanding of children's agency that is very much dependent and unfinished' (p26).

\section{Reconciling the 'I': An 'Analytical Idealism' ontology}

The 'knowing of being' (St Pierre, 2016, p103) needs deeper exploration, not just in current childhood ontologies, but across social sciences. Agency of children, whether viewed from postmodern or posthuman approaches centers on 'the self-present subjectivity of children [that] is left unquestioned' (Oswell, 2016, p16). Kastrup (2017a, $2017 \mathrm{~b}, 2018,2019)$ suggests that the 'l' of experience is situated out of mind, body and time, offering an ontological view that 'makes more sense of reality in a more parsimonious and empirically rigorous manner than mainstream physicalism' (2018p125). Kastrup (2017a, 2017b ,2018, 2019) proposes an Idealism ontology, differing from traditional Idealism in its analytical and logical arguments about the nature of reality, self and experience. Analytical idealism has the potential to 'open viable new avenues for addressing the key questions left unanswered in current platforms' (p126), not only in philosophical and scientific areas, but I would argue, in the field of Childhood Studies. Especially in a climate of posthuman/antihuman theories which posit self as an assemblage of universal forces and fields. Disciplines that are starting to cite Kastrup's work include Philosophy (Sjostedt, 2015), Meteorology (Rowan \& Littlefield, 2018), Education \& Learning (Bilyk \& Sheremet, 2019; Horokhov \& Zhukova, 2018) and Cosmology (Albahari, 2018).

Kastrup (2018) begins by addressing the current problems within mainstream physicalist ontology, that sees reality as constituted by material 'ultimates' that are outside and independent of phenomenal consciousness. It is this ontological premise upon which Childhood Studies is situated in and from where children are viewed as discrete, material objects. Kastrup (2018) posits how experience cannot be reduced to material 'ultimates', that are only constituted by relational qualities (mass, charge and spin). The 'Hard problem of Consciousness' (see Chalmers, 1995) asks how subjective experience can emerge from ultimates. As Kastrup points out, there 'is no fact about ultimates that imply, a priori, facts about experience' Kastrup, 2018, p129). Kastrup (2017a), notes that the objective world is not a self-evident given, in fact 'what we call the world is available to us solely through images -defined here broadly-so to include any sensory modality -on the screen of perception, which itself is consciousness' (p46). This is not to imply a solipsism, where everything exists in a personal mind. Rather, Kastrup $(2017 a, 2018,2019)$ refers to a 'mind at large' (synonymous with 'Cosmic Consciousness' -see Shani, 2015), in which all things (mind and matter) exist within. Physicalism according to Kastrup (2017a) is an 'explanatory model and not a given, used to try to account for correlations between brain activity and inner life, the fact we all inhabit the same world and how the world unfolds independently of personal volition (see Kastrup, 2017a for an extended discussion). We take physicalism for granted, instead of moving to our direct sensory experiences of self and the world. Kastrup (2016, 2017a, 2017b, 2018, 2019) challenges mainstream views of the world as material, in turn raising questions about current ontological and theoretical approaches used in childhood studies. From a critical realist perspective 'the world is understood as material; it is made up of objects, 
structures, relations, mechanisms and powers whose existence is independent of human's perception or knowledge of them' (Larkins, 2019). From an 'Analytical Idealism' perspective, the world is 'mind at large' (see Kastrup, 2016, 2017a, 2018), whose existence is seemingly independent from relative minds. The one subject from which 'relative subjects' (Kastrup, 2018) localise (I point I return to shortly).

Kastrup's 'Idea of the World' (2019), resonates to some degree with Delueze \& Guitarri's 'plane of immanence' that is 'not a concept nor a conceptual field...but it is this plane of immanence that subjects and objects are produced' (Hein, 2016, p135). Kastrup $(2017 a, 2018,2019)$ departs from Delueze \& Guitarri by replacing a flat ontology of materiality with a deep ontology of Consciousness as the ground of reality. For Kastrup, matter is an expression of Consciousness and not a fixed substance. This to some degree resonates with Barad's (2007) theorisation of the material world as 'phenomena in their ongoing materialisation' (Barad, 2007, p152), expanding on Bohr's conception of phenomena and 'our inability, epistemologically, to separate observer from observed' (Hein, 2016, p135). For Childhood Studies, redefining matter within a deeper ontology of Consciousness can begin to reconcile and valuably consider 'the pattern of things behind or below the false surface' (Wenneberg, 2002 cited in Alanen, 2015). Barad (2007) defines phenomena as 'ontologically inseparable of agentially intra-acting components' (p33). As Kastrup argues (2018), to suggest that some ultimates are conscious, raises the problem of how 'micro-level phenomenal parts' (Kastrup, 2018, p135) can constitute macro human subjectivity. This is known as the subject-combination problem, which prompted Cosmopsychisms (see Matthews, 2011; Shani, 2015), to posit a cosmos-as-a-whole ontology; which sees phenomenality (in the forms of mind and matter) as expressions of Consciousness. Subjectivity in Cosmopsychism is an extension to 'force fields, space itself, rather than its restriction to merely matter' (Matthews, 2011 - cited in Kastrup, 2018). Consciousness becomes the only subject, raising then a further problem of 'Decomposition' which Kastrup (2018) addresses. Kastrup (2018) asks, 'how do relative subjects form within cosmic consciousness?' (p134 - see Kastrup, 2018 for an extended discussion on DID and Decomposition); an important consideration for reconciling notions of self, agency and intra-connectedness (see Thomas, Forthcoming). A consciousness-only ontology brings into sharp focus the nature of subjectivity. Adding to debates in Childhood Studies concerned with agency (Larkins, 2019; Oswell, 2017) and the construction of children (Alanen, 2012). Shifting the enquiry from 'how' 'self' is constructed, towards 'what is self'?

\section{From one 'l' to multiple 'I's'}

If we approach the study of childhood from a Consciousness-as-the-only-subject ontology, how do we see and value individual subjects and agency? Can a Consciousness-only ontology offer a wider understanding about the nature of child? In order to address the value of relative subjectivity as an experience, Kastrup (2018), draws upon the work of Shani (2015) who posits 'two intrinsic features of Cosmic Consciousness as constituents of the generic character of each relative subject' (p136). One as a relative 'l' and a core 'l':

'Each relative subject is phenomenally conscious by virtue of the fact that cosmic consciousness is itself intrinsically capable 
of experience. Also, each relative subject has ipesity or I-ness, by which is meant an implicit sense of self which serves as the dative of experience, namely, as that to whom things are given, or disclosed...the claim is then that the sense of I-ness of each relative subject is the sense of I-ness intrinsic to cosmic consciousness as a whole'

(Kastrup, 2018p136)

Kastrup (2018) does not imply a duality in recognising different 'Ipesity'. The 'l' of the relative subject is posited by Kastrup (2018) to be an expression of the core 'l', not separate from it. Relative subjects, therefore, are self-excitations of Consciousness where 'Consciousness has the inherent disposition to self-excitation' ( $\mathrm{p} 140)$. To understand children in this way, is to transcend traditional biological models of child development and narrative as the medium of being (see Frank, 2005). In this sense, children could be viewed as unique assemblages of experiences, experienced by the one subject, essential to each expression. Relative 'l's are manifest and sustained through inner and outer stories, woven by forces which move between private qualitative fields and the whole. The primordial 'l' of relative subjects (that is prior to narrative) is the 'pure dative of experience' (Kastrup, 2018). It is the experiencer. Experiences, therefore, are not 'ontologically distinct from cosmic consciousness, just as the dance is not distinct from the dancer' (Kastrup, 2018. P140). Relative subjects are patterns of self-excitation, in which patterns of experience correspond. For childhood studies, understanding children as a shared core I, temporarily expressing as relative subjects, through the construction of stories, can facilitate a disentanglement from a limited sense of self and experience of the world. In this sense, narrative becomes important in anchoring an assemblage of experiences and for navigating social life. And what is social life? A shared consensus between relative 'l's and their primordial (Consciousness) ' $l$ '. Understanding self in this way, can offer children freedom from self and institutionally imposed definitions of who they are. The 'l' to 'whom things are given or disclosed' (Kastrup, 2018) is the primordial sense of awareness that is prior to inner stories.

\section{'Second attention' epistemology}

For researchers, trying to conceptualise a shift from subjective experiencer to objective witness to a collapse into the only subject, is a conundrum. Epistemological concerns about knowledge and self may need to be approached in different ways. For, if the rationale for doing research with children is to generate valid knowledge about self and experience, then we need to attend to 'the immersion, friction, strain and quivering unease of doing research differently' (Springman \& Truman, 2017). In recognising the story character as a 'relative l', an experience itself, authority and validity of the relative 'l' can be called into question. As Kastrup (2017b) notes 'while identifying with our emotions and thoughts we usually don't identity with experiences mediated by our five senses. In other words, we tend to think that our perceptions - despite still being subjective experiences-are outside us, while our emotions and thoughts are part of $u s^{\prime}(\mathrm{p} 15)$. Supporting children to become researchers of the self as experiencer, before considering wider social relations, requires innovative epistemological approaches. In a 'Transpersonal' approach to learning, Lattuada (2016) proposes a 'second attention epistemology' that allows for a self to observe the relative 'l'; 'a second attention epistemology hypothesizes that pure observation, pure sensation and pure action allows us to transcend the first attention, which perceives reality and identifies with it. 
Second attention instead, observes and dis-identifies with it'(Lattuada, p76). The 'first attention' that Lattuada $(2010,2016)$ refers to, is the attention of the relative subject that perceives, conceptualises (through narratives) and identifies with other objects (taken to include mental and material objects and selves). Lattuada (2010, 2016) refers to 'pure' observation, sensation and action, that can only occur when one shifts into the ' $\mathrm{l}$ ' that is the 'pure dative of experience' (Kastrup, 2018). Self-enquiry involves supporting children, young people and adults (including self as the researcher) to shift into a second attention, from where inner stories can be observed and disentangled from. This involves a re-connection with pure experiential awareness from where the relative 'I' and its stories, can be observed. For a child or young person to become an observer of 'internal' phenomena, without the lens of the conceptual story, can offer a fresh experience of old narratives. Agency is achieved through choice of how one responds (from which 'l' place) to inner and outer phenomena. As opposed to action being a reaction from a relative ' $l$ '. A second attention epistemology offers a higher degree of validity as it transcends personal ideas and concepts about experiences, others and the world. If a group of children, young people and adults move into a second attention, personal, cultural and social differences are transcended.

\section{Shifting from first to second attention epistemology}

Shifting from first to second attention epistemology is a matter of mindfulness. Not the mindfulness applied within a current self-improvement agenda, an 'individualistic practice, within a capitalist culture that enforces the myth of the private self-centred self (Forbes, 2019). Postmodern mindfulness can reinforce a story 'I' when the agenda circles around attainment, behavior and socialisation. Second attention epistemology is a mindfulness invested in enquiry of the self, exploring the knower which behaves as the 'dative of experience' (see - Kastrup, 2018). Both reflexive and discerningly critical of the forces which assemble in the creation of a relative ' $l$ '. It is the aware space from which inner narratives can be reassembled, re-anchored or dissolved. As Sorli (2014) notes, 'according to second attention epistemology research, the common observer in its daily life is only partly aware of how his mind elaboration influences his experience' (Sorli, 2014,p175). Experience remains conceptual and cannot represent a direct lived experience. The origins of the observer is becoming re-understood in Physics, as second attention epistemology offers a 'higher ontological status' (Kaufman, 2018, p163) about knowledge of self, objects and world. In self-enquiry, moving beyond personhood involves a shift from personal narrative, to objective witness as the shared primordial ' $l$ ', resulting in a deep subjectivity. The only subject.

Second attention epistemology can support ethical issues, especially those concerned with power. If children, young people and adults convey self, experience and the world from a second attention space, different relationships form between inner and inner, and inner and 'outer' objects and beings. Second attention epistemology moves beyond 'critical or ethical reflexivity' (see Jackson et al, 2013; Warin, 2011) towards a more 'transpersonal reflexivity' in its transcendence of thought. Foucault (1982) posited critical thought as a means for 'one to get free of oneself and refuse the existence we've been taught is real' (1982, p8). Thought and language, by its nature, is dual and gives rise to/sustains a relative ' $l$ '. Thought as an inner object cannot free another thought, it can only position itself in relation to it, within a dialogical dualism. For one 'to get free of oneself requires a transcendence of thought, via a shift into the 
primordial 'l' of experience. Contemporary practices that rely on philosophical process (see Kizel, 2019) use a 'philosophy-with-children' (Kizel, 2019, p146) approach to 'promote broad critical thinking skills in its young practitioners' (Kizel, 2019, p146). Philosophy-with-children has enormous value in its embodying of philosophy in everyday life, enabling children to discuss 'issues of enormous metaphysical importance' (Kizel, 2019, p146). Yet, the Foucaultian emphasis on critical thought and subversive narrative keeps children at the level of the story 'l'.

\section{The value of a Consciousness-only ontology for Childhood Studies and Research with Children}

The individual narrative as a resource for socialization and belonging can't be ignored but can perhaps be reauthored as a tool for enquiry, rather than a validation of 'self'. For research with children, and the study of childhood, agency is important in a world where children are at the behest of adult's decision-making. It is important therefore to reconcile notions of individual subjectivity with an intra-connected agency (Barad, 2007), so as not to minimise the value of children's experiences in research practice. Discounting a subjective reflexivity without a fuller understanding of 'l', rejects an aspect of self. Whether relative, collective or assembled, the 'l' of experience shouldn't become neglected. ' ' and 'agency' presuppose a being and a doing in the world. Yet agency is entangled with the 'l' and begins when children can hold their 'inner' and 'outer' stories to account, through observation, reflexivity and awareness. Introducing 'Analytical Idealism' (Kastrup, 2019) as a consciousness-only ontological possibility for children (and adults), can add to the interdisciplinary discussions in Childhood Studies, which seek to challenge mainstream ontology which separates and disempowers children (-see Larkins, 2019; Mereweather, 2013). The process of synonymizing self with story sustains worn out ideas of what it means to be human; a paradigm that subtly induces loneliness through individualisation, powerlessness through dependency, and separation through a duality of otherness. The 'social study of childhood, ever since its birth, has been based on social constructionism' (Alanen, p149, 2015), influencing policy, practice and how children are viewed and supported (see Kay et al, 2012). Social constructionism has become a 'transcendent perspective' (Alanen, 2015) across the study of childhood, influencing studies in majority world contexts within an ethos of 'colonial imperialism'; imposing antithetical ideas upon a large percentage of the child population, while claiming that stories manifest the ground of being. A consciousness-first ontology calls for a reauthoring of epistemological understanding and challenges 'the now well-known 'positivist assumptions of scientific enquiry' (Cooper, 2015, pp). The common arguments against positivist ontology call into question empiricism, rationalism and the validity of objectivity (see - Velmans, 2005, 2012; Kastrup, 2017a, 2017b, 2018, 2019; Baruss \& Mossbridge, 2017; Barad, 2007; Radin et al, 2017). This requires a rethinking of traditional research values and a re-defining of what is meant by empirical enquiry. The nature of reality (mind, matter and consciousness) and what it means to be human is subject to new scrutiny across the sciences (Baruss \& Mossbridge, 2017, Radin et al, 2012), opening up a new field of possibilities for the study of childhood. Where narrative as an epistemological lens into the nature of self is called into question.

\section{References}

Aaltola E (2019) Confronting Suffering with Narrative Theory, Constructed Selfhood, and Control: Critical perspectives by Simone Weil and Buddhist metaphysics. Journal of Disability \& Religion: DOI: 10.1080/23312521.2019.1567296 
Alanen, L (2015) Are we all constructionists now? Childhood, 22(2): 149-153.

Albahari M (2016) Beyond cosmopsychism and the great I am: How the world might be grounded in universal 'advaitic' consciousness. In. Kind, A (eds). The Routledge Handbook of Philosophy of the Imagination. London: Routledge

Bamberg M (2011) Who am I? Narration and its contribution to self and identity. Theory \& Psychology, 21(1): 3-24.

Bamberg M and Georgakopoulou A (2008). Small Stories as a new perspective in narrative and identity analysis. Text \& Talk: An Interdisciplinary Journal of Language, Discourse and Communication Studies, 28(3): 377-396

Barad K (2007) Meeting the Universe Halfway: Quantum physics and the entanglement of meaning. London: Duke University Press

Baruss I and Mossbridge $\mathrm{J}$ (2017) Transcendent Mind: Rethinking the science of consciousness. Washington: American Psychological Association

Bennet, J (2005) The Agency of Assemblages and the North American Blackout. Public Culture, 17(3): 445-65

Bilyk V and Sheremet I (2019) A New View of the Nature of Reality and the Teaching Higher-Level Cognitive Strategies. Philosophy and Cosmology, 22: 92-100

Blum-Kulka S (1994) The Dynamics of Family Dinner Talk: Cultural contexts for children's passages to adult discourse. Research on Language and Social Interaction, 27(1): 1-50

Chalmers D (1995) Facing up to the Problem of Consciousness. Journal of Consciousness Studies, 2(3): 200-219

Cherrington $L$ (2003) The use of Māori mythology in clinical settings: Training issues and needs. In. Nikora L.W, Levy, M, Masters, B, Waitoki, W, Te Awekotuku N and Etheredge R.J.M. (Eds). (2003). The Proceedings of the National Māori Graduates of Psychology Symposium 2002: Making a difference, 29-30 November 2002: 117-120

L \& Fairclough N (1999) Language and power in Bourdieu: on Hasan's "the disempowerment game". Linguistics and Education, 10 (4): 399-4

Connolly W (2013) The New Materialism and the Fragility of Things. Journal of International Studies, 41(3): 399-412

Coole D and Frost S (2010) Introducing the new materialisms. In. New Materialisms Ontology, Agency and Politics. In. Coole. D and Frost S. (eds). London: Duke University Press 
Daley K (2013) The Wrongs of Protection and Participation in Research with Marginalised Young People. Journal of Sociology, 51(2): 121-138

Delueze G \& Guittari F (1988) A Thousand Plateaus: Capitalism and schizophrenia. London: Continuum Press

Dennehy R, Cronin M and Arensman E (2019) Involving young people in cyberbulling research: The implementation and evaluation of a rights-based approach. Health Expectations, 22(1): 54-64

Dixon J Ward J and Blower S (2019) They Sat and Actually Listened to what we Think about the Care System: The use of participation, consultation, peer research and co production to raise the voices of young people in and leaving care in England. Child Care in Practice. 25 (1): 6-21

Dore J (1989) Monologue as reinvoicement of dialogue. In. Katherine Nelson (eds). Narratives from the Crib. London: Harvard Uni Press

Forbes D (2019) Mindfulness meditation in America has a capitalist problem. April 7th., retrieved www.vox.com

Foucault M (1982) The subject and power. In. Dreyfus, H. L., \& Rabinow, P (Eds.). Michel Foucault: Beyond structuralism and hermeneutics (2nd ed., pp. 208-226). Chicago, IL: University of Chicago Press

Frank A (1995) The Wounded Storyteller. Chicago University Press: Chicago

Friere P (1970) Cultural Action and Conscientization. Harvard Educational Review, 40(3): $452-477$

Giddens A (1991) Modernity and self-identity: self and society in the late modern age.California: Stanford University Press

Gorin S, Hopper C, Dyson C and Cabral C (2003) Ethical Challenges in Conducting Research with Hard to Reach Families. Child Abuse Review, 17(4): 275-287

Harvey D (1998) The Body as an Accumulation Strategy. Environment and Planning

Hein S (2016) The New Materialism in Qualitative Inquiry: How compatible are the philosophies of Barad and Delueze? Critical Methodologies, 16(2): 132-140

Heinich N (2010) About "social construction." In: The Newsletter of the Research Committee on Sociological Theory, 3-4. Retrieved at: http://www.isasociology. org/pdfs/rc16newsletter-spring-2010.pdf

Hickey-Moody A and Page T (2016) Arts, pedagogy and cultural resistance: New materialisms: London

Horokhov S and Zhukova G (2018) Contemporary Cosmological Paradigms and their Impact on Educational Research. Philosophy and Cosmology, 21: 14-20 
Holloway S and Valentine G (2000) Spatiality and the New Studies of Childhood. Sociology, 34(4): 763-783

James A and Prout A (1995) Sociological Studies of Children. Greenwich: JAI Press.

Jackson S, Backett-Millburn K and Newel E (2013) Researching Distressing Topics: Emotional reflexivity and emotional labor in the secondary analysis of children and young people's narratives of abuse. Open Sage, 0(0): 1-12

Kastrup B (2016) More than Allegory: On religious truth, myth and belief. United Kingdom: John Hunt Publishing

Kastrup B (2017a) An Ontological Solution to the Mind-Body Problem. Philosophies, 2(2):1-18

Kastrup B (2017b) The quest to solve problems that don't exist: Thought artifacts in Contemporary ontology. Studia Humana, 6(4): 45-51

Kastrup, B (2018) The Universe in Consciousness. Journal of Consciousness Studies, 25 (5): 125-155

Kastrup, B (2019) The Idea of the World: A multidisciplinary argument for the mental nature of reality. United Kingdom: John Hunt Publishing

Kaufman S (2018) Experiential Methodology in Consciousness Research. Neuroquantology. 16 (9)

Keahey J (2019) Knowledge in Action: Negotiating power in development. Action Research, 0(0): 1-18

Kizel A (2019) Enabling identity as an ethical tension in a community of philosophical inquiry with children and young adults. Global Studies of Childhood, 9(2): 145-155

Labov W and Waletsky J (1967) Narrative Analysis: Oral versions of personal experience.Essays on the Verbal and Visual Arts: Seattle.

Larkins C (2016) Making the Critical Links: Strategies for connecting marginalised children's action with European citizenship. Revista de Asistenta Sociala, 2: 11-23

Larkins C (2019) Excursions as Corporate Agents: A critical realist account of children's. Childhood, https://doi.org/10.1177/0907568219847266

Lattuada P (2010) Second Attention Epistemology: Truth and reality. Integral Transpersonal Journal, No.0

Lattuada, P (2016) Integral Transpersonal Thinking. Transpersonal Research Colloquium. Anderson R and Calabrese R (eds).

Lewis A (2010) Silence in the Context of 'Child Voice'. Children and Society, 24(1): 14-23

Lloyd P B (2019) Panpsychism and Mental Monism: Comparison and evaluation. 
Retrieved at www.researchgate.net

MacSweeney S, Bowman S and Kelly C (2019) More than just characters in a story: Effective and meaningful involvement of young people in mental health research. Journal of Public Mental Health, 18(1): 14-16

McNamara P (2011) Rights-based narrative research with children and young people conducted over time. Qualitative Social Work, 12(2): 135-152

Mathews F (2011) Panpsychism as paradigm. In. Blamauer M (eds). The Mental as Fundamental, Frankfurt: Ontos Verlag

Mayes E (2016) Shifting research methods with a becoming-child ontology: Cotheorising puppet production with high school students. Childhood, 23(1):105-122

Mayall B (2002) Towards a Sociology for Childhood: Thinking from children's lives. Buckingham: Open University Press

Merewether J (2019) New Materialisms and Children's Outdoor Environments: Murmurative diffractions. Children's Geographies, 17(1): 105-117

Morrow V (2008) Ethical Dilemmas in Research with Children and Young People about their Social Environments. Children's Geographies, 6(1): 49-61

Norrick N (2000) Conversational Narrative: Storytelling in Everyday Talk. Phillidelphia: John Benjamins

Oswell D (2016) Re-aligning children's agency and re-socialising children in childhood studies., In. Esser F, Baadar M, Betz T and Hungerland B. (eds). Reconceptualising Agency and Childhood: New perspectives in childhood studies, (19-34. London: Routledge

Radin D, Micheal L, Galdamez K, Wendlend P, Rickenbach P and Delorme A (2012) Consciousness and the double-slit interference pattern: Six experiments. Physics Essays, 25(2): DOI: 10.4006/0836-1398-25.2.157

Rekret P (2018) The Head, the Hand, and Matter: New Materialism and the politics of knowledge. Theory, Culture \& Society, 35(7-8): 49-72

Sandberg S (2016) The importance of stories untold: Life-story, event-story and trope. Crime Media Culture, 12(2):153 -171

Shani I (2015) Cosmopsychism: A holistic approach to the metaphysics of experience. Philosophical Papers, 44(3): 389-347

Simonsen K (2012) Embodiement, experience and phenomenology as critical geography. Human Geography, 37(1): 10-21

Sjostedt P (2015) Noumenautics: Metaphysics, metaethics, psychedelics. United 
Kingdom: Psychedelic Press

Sorli A (2014) On the Origin of the Observer. American Journal of Modern Physics, 3(4): 173-177

St Pierre E A, Jackson A and Mazzei L A (2016) New empiricisms and new materialisms: Conditions for new inquiry. Critical Methodologies, 16(2): 99-110

Spivak G C (1974) Translator's preface. In J. Derrida (Ed.) \& G. C. Spivak (Trans.), Of grammatology (pp. ix-xc). Baltimore, MD: Johns Hopkins University Press.

Thornborrow J (2007) Narrative Opinion and Situated Argument in Talk Show Discourse. Journal of Pragmatics, 39(8): 1-19

Thomas D M (2019) Child as 'Alter': Re-understanding children and experience in a consciousness-only ontology. (Forthcoming)

Uprichard E (2008) Children as 'Becomings' and 'Beings': Children, childhood and temporality. Children and Society, 22(4): 303-313

Warin J (2011) Ethical mindfulness and reflexivity: managing a research relationship with children and young people in a 14 year-long qualitative longitudinal research study. Qualitative Inquiry, 17(9): 805-819

Water T, Payam S, Tokolahi E, Reay S and Wrapson J (2018) Ethical and practical challenges of conducting art-based research with children/young people in the public space of a children's outpatient department. Journal of Child Health Care.

https://doi.org/10.1177/1367493518807318 